\title{
Structure and tribological properties of DLC:Si/AICrN low friction thin film
}

\author{
Agnieszka Paradecka ${ }^{1, *}$, Krzysztof Lukaszkowicz ${ }^{1}$, and Mirosława Pawlyta ${ }^{1}$ \\ ${ }^{1}$ Silesian University of Technology, Institute of Engineering Materials and Biomaterials, Konarskiego 18A, 44-100 Gliwice, Poland
}

\begin{abstract}
A wide range of diamond-like carbon coatings is caused by their structure composed of $\mathrm{sp}^{2}$ and $\mathrm{sp}^{3}$ carbon hybridisation and the possibility of both metallic and non-metallic admixtures or the creation of a hydrogenated form. One of the ways to improve the tribological properties of DLC is to dope it with silicon. Deposited on stainless steel substrate coating system composed of AlCrN film covered by DLC:Si was the subject of the studies. The AlCrN and DLC:Si layers were deposited by PVD lateral rotating ARCcathodes and PACVD on the X6CrNiMoTi17-12-2 steel respectively. Characteristics of DLC:Si film was performed by imaging the topography using SEM and AFM. The structure was investigated using a Raman spectroscopy and HRTEM. Tribological and adhesion tests were carried out using a ball-on-disc and a scratch test respectively. Tests using the TEM confirmed an amorphous character of DLC:Si layer. A phase composition analysis of the DLC:Si layer with the Raman spectroscopy method showed the presence of bonds distinctive for diamond $\left(\mathrm{sp}^{3}\right)$ and graphite $\left(\mathrm{sp}^{2}\right)$, typically observed in DLC coatings. Under the technically dry friction conditions, the friction coefficient for the associations tested is within the range 0.14 for the investigated coating.
\end{abstract}

\section{Introduction}

The evaluation of tribological arrangements is mainly carried out by the coefficient of friction (COF) [1]. Currently, there is a number of coatings with good tribological properties. However, developing technology and reduction of the use of traditional lubricants for environmental reasons forces the efficiency of tribological thin films to increase. Reducing friction also leads to energy savings and extends the life of the machine components [2-4]. Hence, carbon-based films like DLC attracted considerable attention. It is required that such a coating significantly reduces friction and protects elements often working in extreme variable conditions, i.e. high temperature or high speed [3].

DLC is a metastable amorphous form of carbon, with a predominance of $\mathrm{sp}^{3}$ bonds. These coatings are characterised by high hardness, wear resistance, chemical and electrochemical resistance, low coefficient of friction and biocompatibility [1, 2, 4-7]. The main variables in DLC coatings are the carbonisation hybridisation $\left(\mathrm{sp}^{1}, \mathrm{sp}^{2}\right.$ and $\left.\mathrm{sp}^{3}\right)$ and hydrogen $\mathrm{H}$ content [8]. Depending on their distribution and the presence of hydrogen, they can be divided into several types of DLC. The main four types of amorphous carbons are polymerlike a-C:H (PLCH); diamond-like a-C:H (DLCH); hydrogenated tetrahedral amorphous carbon films (ta$\mathrm{C}: \mathrm{H})$; and graphite-like a-C:H (GLCH) $[9,10]$.

However, DLC has no unique composition, and it is a mixture of amorphous and crystalline phases, consisting of a cluster of 3-coordinated $\mathrm{sp}^{2}$ bonds embedded in a $\mathrm{sp}^{3}$ bonded matrix [4]. It is assumed that $\mathrm{sp}^{2}$ is responsible for electronic, and $\mathrm{sp}^{3}$ for mechanical, tribological and corrosion resistive properties. The construction of $\mathrm{sp}^{3}$ and $\mathrm{sp}^{2}$ bonds and their ratio is controlled by the deposition process, to adapt mechanical properties to specific needs [5].

Modification of individual properties of diamond-like films, such as electrical or mechanical ones, can be carried out by introducing various additions, both metallic ( $\mathrm{Me}=\mathrm{W}, \mathrm{Ti}$, Mo, etc.) and non-metallic $\left(\mathrm{X}=\mathrm{Si}, \mathrm{O}_{2}, \mathrm{~N}_{2}\right)[1,11]$. Carbon nitrides (a-C:N, ta-C:N, a-C:H: N, ta-C:H:N) belong to another group of carbon films [1].

In order to improve the tribological properties and reduce the coefficient of friction, some additions can be added to the DLC matrix, for example, silicon, titanium, tungsten etc. [6]. In comparison to DLC, good results, particularly in the humid atmospheres, can be observed for high ranges of silicon $(10 \div 40 \%)$. At the same time, the admixture improves corrosion resistance, thermal stability as well as reduces internal stresses, which prevents formation of microcracks [2, 3, 12]. Also, in the case when there is a need to increase the share of $\mathrm{sp}^{3}$ bonds, it is possible by increasing the amount of silicon precursor (silane $\left.\mathrm{SiH}_{4}\right)[6,13]$.

For thin a-C based films, $\mathrm{Cr}$ or Ti interlayers are used to increase adhesion to the substrate, to obstruct diffusion of carbon to the substrate and to reduce high residual stresses, which enables them to carry higher loads (especially when they are mounted on the soft substrate) $[1,14]$. Another way is to improve ductility by adding metallic phases (e.g. $\mathrm{Cu}, \mathrm{Ni}, \mathrm{Ag}$ ). An equally

\footnotetext{
*Corresponding author: agnieszka.paradecka@polsl.pl
} 
effective method is to create a multilayer repeated periodically or layers of different structures (different ratio of $\mathrm{sp}^{3} / \mathrm{sp}^{2}$ ) [5]. The use of the process of biasgraded deposition using magnetron sputtering has achieved moderate hardness, but very high strength (plasticity of 57.6\%) [1].

DLCs are excellent candidates for use as films on implants, used in the machining, the automotive industry, the metallurgical industry, the computer including MEMS or pharmaceutical industry [1]. They are also used as anti-reflective coatings, solar cells, protective against corrosion because they are inert to even strong mixtures of acids $[4,5,8]$. It is worth noting that the coating can be deposited at low substrate temperatures $\left(<200^{\circ} \mathrm{C}\right.$. $)$ This enables their use also steel components which are temperature sensitive and plastics $[8,15]$.

The aim of this paper was to examine the microstructure and tribological properties of DLC:Si/AlCrN thin film deposited on the austenitic steel X6CrNiMoTi17-12-2.

\section{Materials and methodology}

The study was conducted on coatings consisting of DLC:Si top layer and hard AlCrN layer deposited on the X6CrNiMoTi17-12-2 austenitic steel substrate. The investigated coatings were applied to disks with dimensions: $35 \mathrm{~mm}$ diameter, $10 \mathrm{~mm}$ thickness. The substrate was heated to a suitable temperature and then purified by the argon ions. In order to increase the adhesion of the coating to the substrate, an additional interlayer of $\mathrm{CrN}$ was applied. The AlCrN layer was deposited by $\pi 1511$ based on PLATIT's rotating and planar ARC-technology. Cathodes containing pure $\mathrm{Cr}$ and $\mathrm{Al}$ were used. Top layers consisting of DLC with $\mathrm{Si}$ addition, deposited by Plasma Assisted Chemical Vapour Deposition (PACVD) method. Process parameters are presented in Table 1.

Table 1. Coating deposition parameters.

\begin{tabular}{|c|c|c|}
\hline Parameter & AlCrN & DLC:Si \\
\hline Working pressure $[\mathrm{Pa}]$ & 3 & 2 \\
\hline Substrate bias voltage $[\mathrm{V}]$ & 60 & 500 \\
\hline Arc of target $[\mathrm{A}]$ & $250 / 235$ & - \\
\hline Process temperature $\left[{ }^{\circ} \mathrm{C}\right]$ & 450 & 220 \\
\hline Time $[\mathrm{s}]$ & 4200 & 3900 \\
\hline
\end{tabular}

The topography studies of the DLC:Si/AlCrN sample were carried out by atomic force microscope (AFM) Park System X E-100 in non-contact mode. The measurements were made in the $5 \times 5 \mu \mathrm{m}$ scanning ranges. Five measurements were carried out during the test. Topography was also examined by scanning electron microscope SUPRA 35 by ZEISS.

During the observation of the microstructure, TITAN 80-300 ultrahigh resolution scanning/transmission electron microscope was used. Previously, thin crosssection lamellas were prepared by reducing the thickness of micro-samples on both sides of the focused beam of gallium ion $(\mathrm{Ga}+)$, using by Quanta $200 \mathrm{i}$ instrument, in order to obtain a thin film having a thickness of about $100 \mathrm{~nm}$.

Raman measurements were performed at room temperature with a Via-Raman microscope (Renishaw) with an ion-argon laser, wavelength of $514 \mathrm{~nm}$, and resolution of $1 \mathrm{~cm}^{-1}$.

In order to verify the tribological properties of thin films, adhesion, the coefficient of friction and wear test were carried out. Adhesion of the coating to the substrate was measured using Revetest scratch tester (CSEM Instrument), by moving the diamond indenter with of increasing the load along the surface of the sample. The tests were made using the following parameters: load range: $0-100 \mathrm{~N}$, load increase rate $(\mathrm{dL} / \mathrm{dt}): 100 \mathrm{~N} / \mathrm{min}$, indenter's sliding speed $(\mathrm{dx} / \mathrm{dt}): 10 \mathrm{~mm} / \mathrm{min}$.

Ball-on-disc test was used to determine the coefficient of friction and coating wear rate (based on the weight loss of the sample). The tests were carried out on the THT (CSM Instruments) device with the following parameters: sliding speed: $0.2 \mathrm{~m} / \mathrm{s}$; normal load: $10 \mathrm{~N}$; counterpart: $\mathrm{Al}_{2} \mathrm{O}_{3}$ ball of $6 \mathrm{~mm}$ diameter; sliding distance: $1000 \mathrm{~m}$; temperature: $23^{\circ} \mathrm{C}\left( \pm 1^{\circ} \mathrm{C}\right)$; relative humidity: $26 \%( \pm 3 \%)$. Three measurements were carried out during the test. Analysis of coating wear and identification of the chemical composition in microareas were carried out using scanning electron microscopy (SEM) Zeiss Evo MA10 and Bruker XFlash $₫ 5010$ EDS spectrometer respectively.

\section{Results and discussion}

Examination of the surface topography of the sample using SEM (Fig. 1) revealed the characteristic surface structure in the form of individual drop-like microparticles, which are typically caused by the arc evaporation and PACVD deposition process.

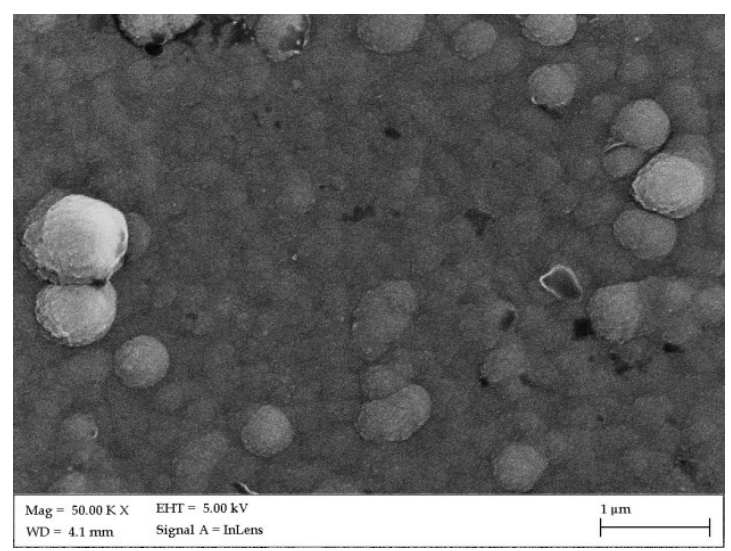

Fig. 1. The surface topography of DLC:Si/AlCrN coating.

AFM studies (Fig. 2) made it possible to analyse the development of the surface that defines the ratio of the actual surface area measured, which according to its orthogonal projection, onto the plane $\mathrm{XY}$, is $2.63 \%$. The surface roughness of the thin films (Ra) was also determined during the tests. Average roughness for DLC:Si is $28 \pm 7 \mathrm{~nm}$, root mean square (RMS) $-49 \pm 13$ $\mathrm{nm}$ and $\mathrm{Ra}_{\max }-346 \pm 56 \mathrm{~nm}$.

The histogram presented in Fig. 3 shows that the vast majority of the studied area was contained in mean 
roughness values. Only a few points determined the maximum value.

Friction coefficient tests (Fig. 4) carried out under dry conditions showed that DLC:Si/AlCrN coatings had good tribological properties and the coefficient of friction was 0.14 which was convergent with literature data [16-18], and there was no mass loss of the sample or counter-product during the test (Tab. 2). After the tests, surface observation (Fig 5) and its chemical analysis were also carried out (Tab. 3). The results confirmed that the coating was not interrupted.

The discrepancy in the chemical composition in points 4 and 6 are the results from the discovery of the AlCrN film. However, this is not caused by the damage of the DLC film during the test. Visible circular craters are the result of falling drops of the deposited material while cooling, which occurs after the finished of the coating process, what is typical for the deposition of coatings by the arc method.

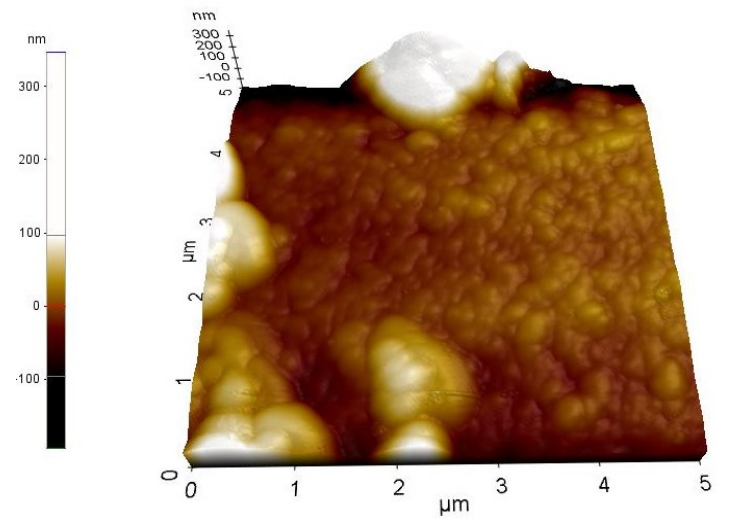

Fig. 2. Three-dimensional AFM images of DLC:Si/AlCrN coating.

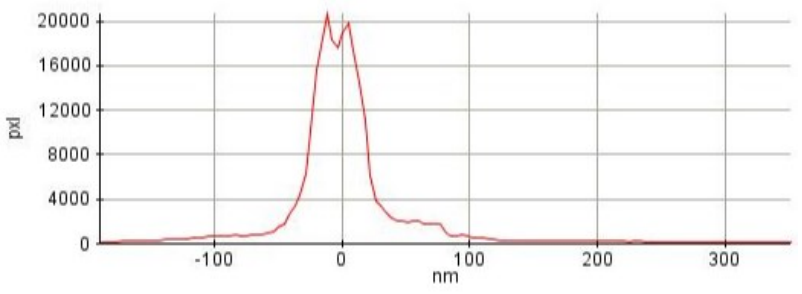

Fig. 3. Region histogram for DLC:Si/AlCrN coating.

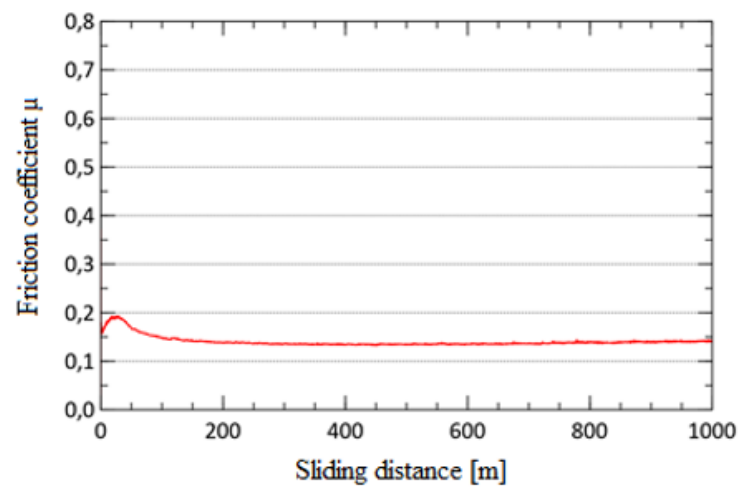

Fig. 4. Dependence of the friction coefficient on the sliding distance during the wear test for DLC:Si/AlCrN coating.

The critical load values, which characterise the adhesion of the coating to the substrate, were determined using the scratch test method (Fig. 6).

The combination of microscopic observations, measurements of acoustic emission, and a linearly increasing load allows to determine the value of the load responsible for the first cohesion damage $\left(\mathrm{Lc}_{1}\right)$, adhesive damage $\left(\mathrm{Lc}_{2}\right)$ and total damage $\left(\mathrm{L}_{\mathrm{C} 3}\right)$. The results of the study are presented in Table 4. DLC:Si/AlCrN coating has a very good value of the critical load.

Table 2. The average value of the friction coefficient and the weight loss of test materials.

\begin{tabular}{|c|c|c|c|c|c|c|c|c|}
\hline \multirow{3}{*}{ DLC:Si } & \multicolumn{2}{|c|}{$\boldsymbol{\mu}$} & \multicolumn{2}{c|}{ weight of sample, $\mathbf{g}$} & \multicolumn{2}{c|}{ weight of ball, $\mathbf{g}$} & \multicolumn{2}{c|}{ weight loss, $\mathbf{g}$} \\
\cline { 2 - 9 } & avg. & stdev & before & after & before & after & sample & ball \\
\cline { 2 - 8 } & 0.140 & 0.019 & 47.7424 & 47.7424 & 0.4453 & 0.4453 & 0.0000 & 0.0000 \\
\hline
\end{tabular}

a)

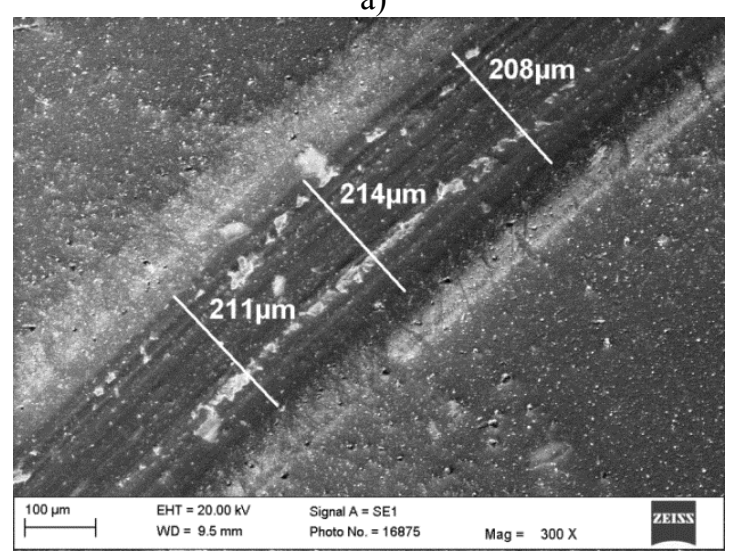

b)

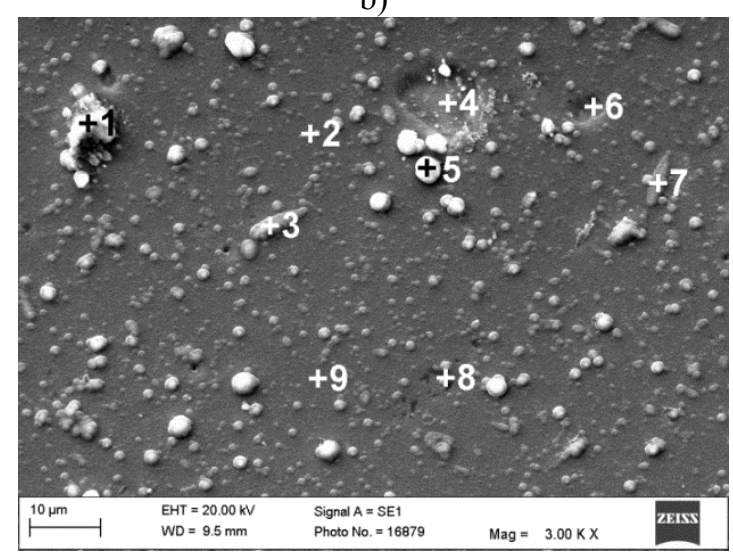

Fig. 5. Wear surface of the DLC:Si/AlCrN. 
Table 3. Results of the chemical composition analysis for points shown in Fig. 4b.

\begin{tabular}{|c|c|c|c|c|c|c|c|c|c|}
\hline \multirow{2}{*}{ Elements } & \multicolumn{8}{|c|}{ The content of elements in points, wt.\% (normalized to 100\%) } \\
\cline { 2 - 12 } & $\mathbf{1}$ & $\mathbf{2}$ & $\mathbf{3}$ & $\mathbf{4}$ & $\mathbf{5}$ & $\mathbf{6}$ & $\mathbf{7}$ & $\mathbf{8}$ & $\mathbf{9}$ \\
\hline $\mathbf{C}$ & 67.7 & 59.8 & 56.6 & 4.2 & 63.6 & 16.9 & 60.0 & 58.3 & 55.4 \\
\hline $\mathbf{N}$ & 0.2 & 0.1 & 0.1 & 20.3 & 2.4 & 16.5 & 0.2 & 0.3 & - \\
\hline $\mathbf{A l}$ & 4.9 & 6.7 & 5.1 & 24.3 & 5.9 & 18.5 & 8.4 & 7.0 & 7.9 \\
\hline $\mathbf{S i}$ & 3.0 & 3.0 & 2.8 & - & 2.6 & 0.4 & 2.7 & 2.8 & 2.5 \\
\hline $\mathbf{C r}$ & 23.0 & 30.3 & 35.3 & 51.3 & 25.5 & 47.7 & 32.8 & 31.6 & 34.2 \\
\hline $\mathbf{T i}$ & 1.3 & - & - & - & - & - & - & - & - \\
\hline
\end{tabular}

Load force Fn, N

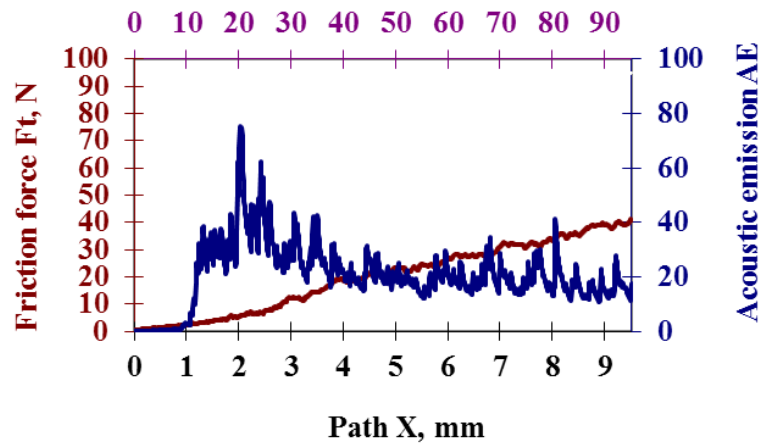

Fig. 6. Dependence of the acoustic emission (AE) and friction force Ft on the load force Fn during the scratch test for DLC:Si/AlCrN.
Table 4. Results obtained in scratching tests for the DLC:Si/AlCrN coating.

\begin{tabular}{|c|c|c|}
\hline $\mathbf{L} \mathbf{C 1}, \mathbf{N}$ & $\mathbf{L} \mathbf{C}, \mathbf{N}$ & $\mathbf{L} \mathbf{C}, \mathbf{N}$ \\
\hline $9.8 \pm 0.9$ & $15.5 \pm 1.9$ & $32.8 \pm 1.6$ \\
\hline
\end{tabular}

In order to characterise the structure of the thin films STEM and TEM mode imaging was used applied for selected areas. In Figure 7 the bright- and dark-field images of the AlCrN are presented, as well as a corresponding diffraction pattern. $\mathrm{AlCrN}$ has a nanocrystalline structure with a column structure of the grain. The cross-sectional studies of the $\mathrm{AlCrN}$ layer show a homogeneous, compact structure.

The HRTEM image of the DLC:Si exhibit amorphous nature of the thin films (Fig. 8 a). The resulting diffraction patterns show a considerable broadening of the diffraction rings (Fig. 8 b).

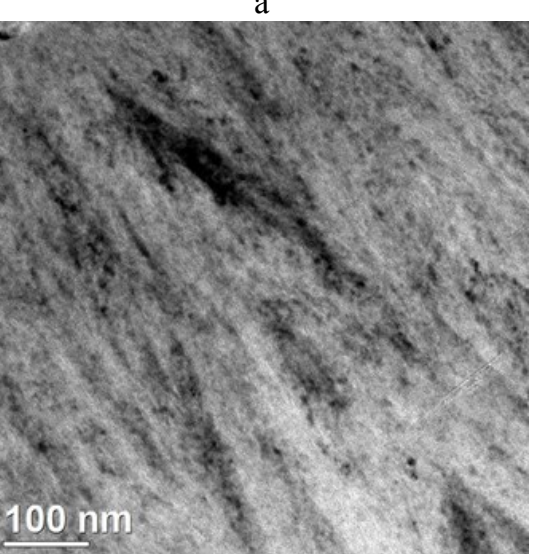

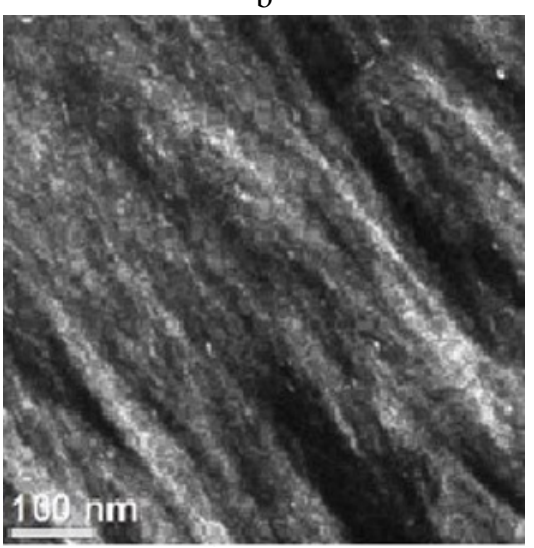

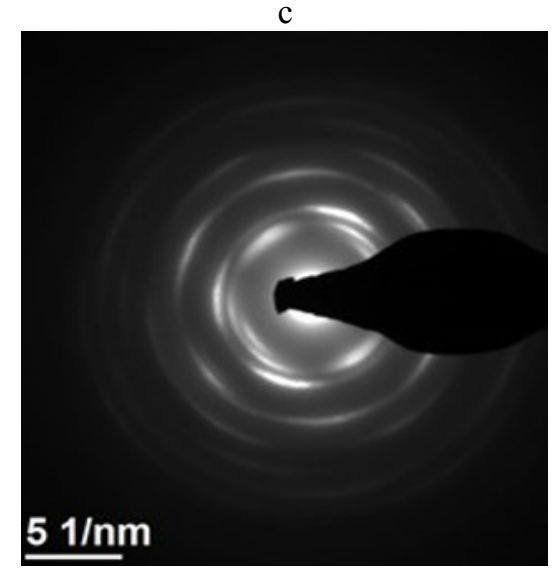

Fig 7. Structure of the AlCrN coating: a) TEM bright-field image, b) TEM dark field image, c) corresponding SAED pattern.

a

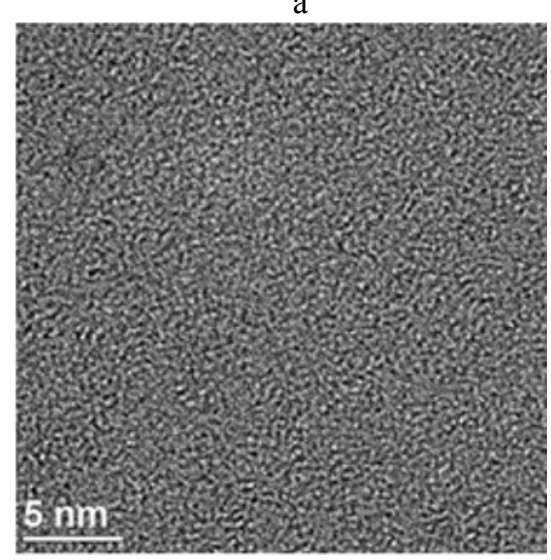

b

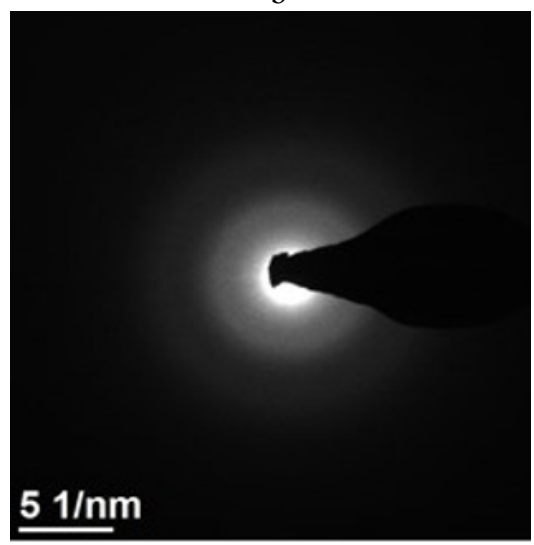

Fig 8. Structure of the DLC:Si thin films : a) HRTEM image, b) SAED pattern. 
The carbon may take an allotropic form, such as diamond $\left(\mathrm{sp}^{3}\right)$, giving a strong and sharp peak at 1332 $\mathrm{cm}^{-1}$ or graphite $\left(\mathrm{sp}^{2}\right)$, which is in crystalline forms a band at $1580 \mathrm{~cm}^{-1}$ (G peak). However, graphite is more common in an amorphous form, which results in widening and shifting the band $\left(1500 \mathrm{~cm}^{-1} \div 1700 \mathrm{~cm}^{-1}\right)$. The second active band $\mathrm{D}$ is prepared by distorting the structure formed by the addition of $\mathrm{sp}^{3}$ bonds or $\mathrm{H}$, N. It can accept bands within a range $1200 \mathrm{~cm}^{-1} \div 1450 \mathrm{~cm}^{-1}$. In Fig. 9, the visible spectrum of the amorphous form of a coating can be observed. The curves are corresponding to both bands, were fitted using Lorentzian curves. For the investigated thin film, the $\mathrm{G}$ band is $1557 \mathrm{~cm}^{-1}$ and D band is $1342 \mathrm{~cm}^{-1}$. The shift of the peak $\mathrm{G}$ in relation to the pure crystalline form is the result of the addition of silicon to the film. Parameter describing the nature of $\mathrm{sp}^{2}$ bond are the ratio of peaks intensities $[19,20]$. If the silicon content was higher than the $\mathrm{I}_{\mathrm{D}} / \mathrm{I}_{\mathrm{G}}$ ratio would be smaller $[17,21]$. The $\mathrm{I}_{\mathrm{D}} / \mathrm{I}_{\mathrm{G}}$ ratio for $\mathrm{DLC}: \mathrm{Si} / \mathrm{AlCrN}$ in this case is 0.73 .

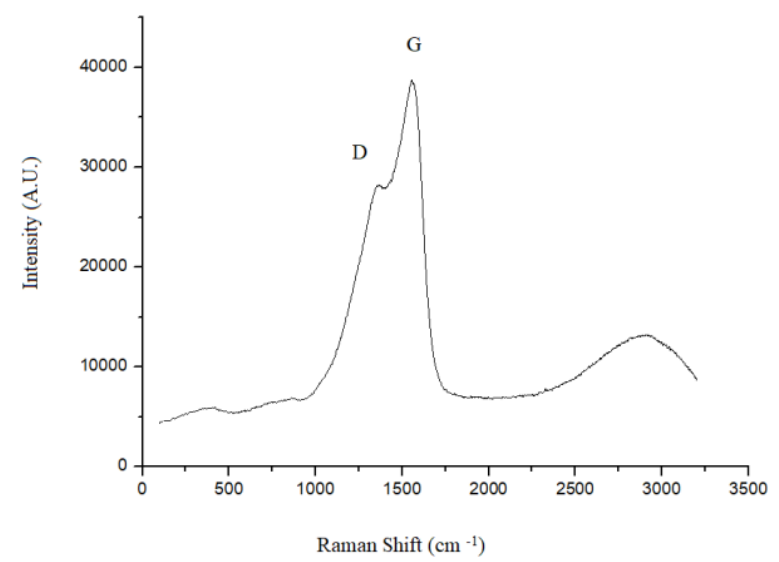

Fig. 9. Raman spectra of DLC:Si/AlCrN coating.

\section{Conclusion}

The DLC:Si/AlCrN coating was deposited successfully on the X6CrNiMoTi17-12-2 steel substrate. TEM studies reveal the nanocrystalline structure of the AlCrN layer and the amorphous nature of the DLC:Si thin films. A phase-composition analysis of the DLC layer with the Raman-spectroscopy method showed the presence of bonds distinctive for diamond $\left(\mathrm{sp}^{3}\right)$ and graphite $\left(\mathrm{sp}^{2}\right)$, typically observed in diamond-like carbon coatings. Under dry-friction conditions, the friction coefficient for the associations tested is 0.14 for the DLC:Si/AlCrN coating. The investigated coating reveals high wear resistance as well as good adhesion to the substrate.

\section{References}

1. C. A. Charitidis, Int J Refract Met H; 28, 1, (2010)

2. I. Tanaka, T. Nakano, H. Kousaka, H. Hashitomi, Surf Coat Tech, 332 (2017)

3. A. Amanov, T. Watabe, R. Tsuboi, S. Sasaki, Surf Coat Tech, 232 (2013)

4. R. Sharma, P. K. Barhai, N. Kumari, Thin Solid Films, 516, 16, (2008)

5. M. R. Price, B. Raeymaeker, Acta Mater, 141 (2017)

6. D. Bociaga, A. Sobczyk-Guzenda, W. Szymanski, A. Jedrzejczak, A. Jastrzebska, A. Olejnik, K. Jastrzebski, Appl Surf Sci, 417 (2017)

7. I. Masami, N. Setsuo, S. Tsutomu, C. Junho, Nucl Instrum Meth B, 267, 8-9 (2009)

8. D. Hofmann, S. Kunkel, K. Bewilogua, R. Wittorf, Surf Coat Tech, 215 (2013)

9. M. Lubwama, B. Corcoran, K. V. Rajani, C. S. Wong, J. B. Kirabira, A. Sebbit, K. A. McDonnell, D. Dowling, K. Sayerse, Surf Coat Tech, 232 (2013)

10. D. W. Ren, Q. Zhao, A. Bendavid, Surf Coat Tech, 226 (2013)

11. J. Vetter, Surf Coat Tech, 257 (2014)

12. X. Wu, M. Suzuki, T. Ohana, A. Tanaka, Diam Relat Mater, 17, 1 (2008)

13. D. Batory, A. Jedrzejczak, W. Kaczorowski, W. Szymanski, L. Kolodziejczyk, M. Clapa, P. Niedzielski, Surf Coat Tech, 271 (2015)

14. E. L. Dalibon, J. N. Pecina, A. Cabo, V. J. TravaAiroldi, S. P. Brühl, J Mater Res Tech (to be published)

15. J. C. Damasceno, S. S Camargo Jr., M. Cremona, Thin Solid Films, 420-421 (2002)

16. O. R. Monteiro, M.-P. Delplancke - Ogletree, Surf. Coat Tech, 163-164, (2003)

17. T.F. Zhang, Z.X. Wan, J.C. Ding, S. Zhang, Q.M. Wang, K.H. Kim, Appl Surf Sci,435 (2018)

18. J. Robertson, Mat Sci Eng R, 37, 4-6 (2002)

19. S.C. Ray, W.F. Pong, P. Papakonstantinou, Thin Solid Films 601 (2016)

20. S.C .Ray, T.I T .Okpalugo, C.W. Pao, H.M. Tsai, J.W. Chiou, J.C. Jan, W.F. Pong, P. Papakonstantinou, J.A. McLaughlin, W.J. Wang, Mater Res Bull 40 (2005)

21. J. Choi, M. Kawaguchi, T. Kato, M. Ikeyama, Microsyst Technol 13 (2007) 